\title{
NUCLEAR FACTOR-kB CONTROLS THE REAGGREGATION OF 3D NEUROSPHERE CULTURES IN VITRO
}

\author{
D Widera, I Mikenberg, A Kaus, C Kaltschmidt\#, B Kaltschmidt"**
}

\author{
Institut für Neurobiochemie, Universität Witten/Herdecke, Stockumer Str. 10, D-58448 Witten, Germany \\ \#: equal contribution
}

\begin{abstract}
The approach of reaggregation involves the regeneration and self-renewal of histotypical 3D spheres from isolated tissue kept in suspension culture. Reaggregated spheres can be used as tumour, genetic, biohybrid and neurosphere models. In addition the functional superiority of 3D aggregates over conventional 2D cultures developed the use of neurospheres for brain engineering of CNS diseases. Thus 3D aggregate cultures created enormous interest in mechanisms that regulate the formation of multicellular aggregates in vitro. Here we analyzed mechanisms guiding the development of 3D neurosphere cultures. Adult neural stem cells can be cultured as self-adherent clusters, called neurospheres. Neurospheres are characterised as heterogenous clusters containing unequal stem cell subtypes. Tumour necrosis factor- $\alpha$ (TNF- $\alpha$ ) is one of the crucial inflammatory cytokines with multiple actions on several cell types. TNF- $\alpha$ strongly activates the canonical Nuclear Factor Kappa-B (NF-KB) pathway. In order to investigate further functions of TNF in neural stem cells (NSCs) we tested the hypothesis that TNF is able to modulate the motility and/or migratory behaviour of SVZ derived adult neural stem cells. We observed a significantly faster sphere formation in TNF treated cultures than in untreated controls. The very fast aggregation of isolated NSCs $(<2 h)$ is a commonly observed phenomenon, though the mechanisms of $3 \mathrm{D}$ neurosphere formation remain largely unclear. Here we demonstrate for the first time, increased aggregation and enhanced motility of isolated NSCs in response to the TNF-stimulus. Moreover, this phenomenon is largely dependent on activated transcription factor NF- $\mathrm{KB}$. Both, the pharmacological blockade of NF- $\kappa \mathrm{B}$ by pyrrolidine dithiocarbamate (PDTC) or Bay11-7082 and genetic blockade by expression of a transdominant-negative super-repressor IкB-AA1 led to decreased aggregation.
\end{abstract}

Keywords: neural stem cell, neurosphere, TNF-alpha, aggregation, cell motility, Nuclear Factor-kappaB, IkappaB, neurosphere formation, somatic stem cell, reaggregation, tissue culture, $3 \mathrm{D}$

\section{*Address for correspondence: \\ Dr. B. Kaltschmidt, \\ Universität Witten/Herdecke, \\ Institut für Neurobiochemie, \\ Stockumer Str. 10, \\ D-58448 Witten. \\ Germany}

Tel: +49 (0) 2302669128

Fax: +49 (0) 2302669220

E-Mail: b.kaltschmidt@uni-wh.de

\section{Introduction}

Improved cell culture techniques are important to generate sufficient number of undifferentiated cells for cell replacement therapies, which are in need of many different cell types, for example in brain diseases. A well established culture system for adult neural stem cells is the 3D neurosphere culture. As discussed by Layer et al. reaggregated neurosphere culture have numerous advantages in tissue engineering (Layer et al., 2002). Neural stem cells (NSCs) are progenitors of neurons and glial cells with the ability to proliferate, migrate and integrate into neuronal tissues. Many recent reports show regenerative capacity of stem cells either due to replacement and functional integration (Heine et al., 2004) or due to secretion of neuroprotective factors (Pluchino et al., 2005). These cells can be efficiently isolated from subventricular zone (Doetsch et al., 1999; Johansson et al., 1999) and dentate gyrus of the hippocampus (Roy et al., 2000). In vitro, NSCs grow as floating clusters called neurospheres (Rao, 1999).

These isolated clusters are characterised by the expression of the intermediate filament Nestin (Lendahl et al., 1990), the RNA-binding protein Musashi (Sakakibara et al., 1996; Sakakibara et al., 2002), the transcription factors Sox1 (Pevny et al., 1998) and Sox 2 (Brazel et al., 2005) and the absence of differentiation markers such as $\beta$-III-tubulin for immature neurons and glial fibrillary acidic protein (GFAP) for glial cells.

One of the crucial features of stem cells is their selfrenewal capacity. There are many reports on substances or conditions leading to increased proliferative behaviour of neural stem cells. Interestingly, most of them are strictly linked to the NF-KB pathway. On the other hand also migration inducing factors such as stromal cell-derived factor-1 (SDF-1) or monocyte chemoattractant protein1 (MCP-1) are regulated by this important transcription factor (see Widera et al., 2006 for review). Moreover, in the nervous system NF- $\mathrm{KB}$ plays an important role in neuroprotection and neurodegeneration, memory consolidation and learning (see Kaltschmidt et al., 2005 for review).

Since the early nineties several isolation and culture protocols for adult neural stem cells have been established (Reynolds and Weiss, 1992; Gage et al., 2000; McKay et al.,, 1997; Rao, 1999). Most of these culture protocols use uncoated cell culture flasks or chambers leading to formation of 3D neurospheres analogue to embryoid bodies formed by embryonic stem cells. Neurospheres generated from various anatomical regions of the brain e.g. subventricular zone (SVZ) can perform self-renewal in vitro (Fig.1). Hence, such 3D neurosphere cultures might be an optimal source for engineered brain tissue. However, the mechanism leading to $3 \mathrm{D}$ neurosphere 


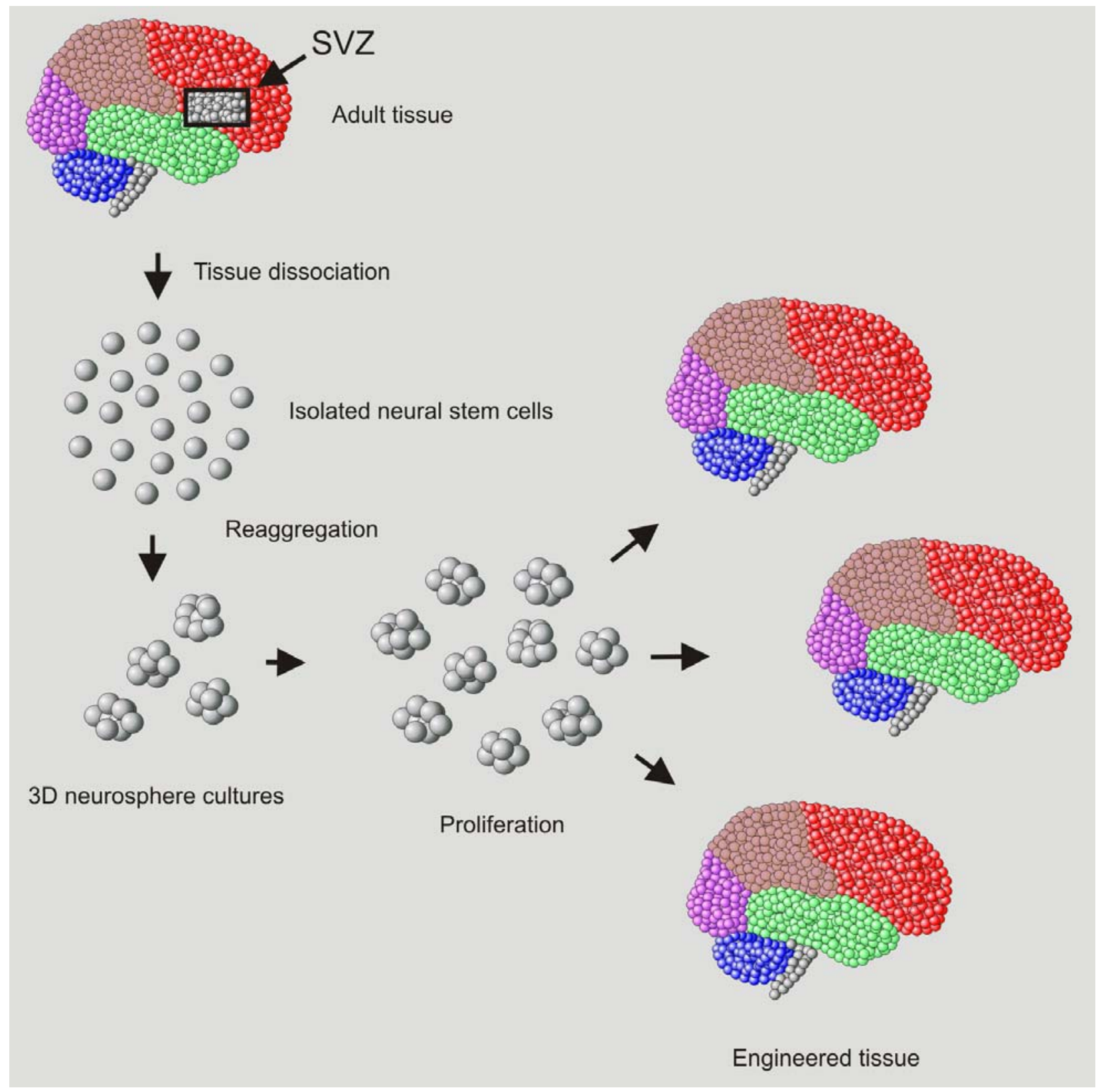

Figure 1. Preparation and potential use of 3D neurosphere cultures. Cellular structure of adult brain is indicated as different coloured beads. Cells from the subventricular zone (SVZ) are dissociated and form reaggregated $3 \mathrm{D}$ neurospheres. Neurospheres do self-renew via proliferation and can be used as a replenishable resource for engineered brain tissue and for potential therapeutic use.

formation - in other words the aggregation of single cells to clusters remains largely unclear.

In this approach we tested the influence of TNF- $\alpha$ on motility and aggregation of NSCs. Here we provide evidence of TNF- $\alpha$ mediated and NF- $\kappa B$ dependent aggregation of isolated adult neural stem cells. First we analyzed the expression of biomarkers in NSCs cultured as neurospheres. The deployed cells were positive for typical neural stem cell markers such as Nestin or Musashi and were negative for differentiation markers such as $\beta$ III-tubulin for neurons, GFAP for glial cells and A2B5 for oligodendrocyte precursors. In this system TNF- $\alpha$ strongly activated NF- $\kappa \mathrm{B}$. Using time-lapse videomicroscopy we demonstrated largely accelerated reaggregation of dissociated, TNF treated neurosphere derived cells. Both, the pharmacological inhibition and transcriptional blockade of the NF- $\kappa \mathrm{B}$ pathway resulted in attenuation of aggregation. Finally, TNF treatment had no influence on stemness of the here analyzed NSCs.

\section{Materials and Methods}

\section{Isolation and culture of adult neural stem cells (NSCs)}

Adult rats were killed by decapitation. NSCs were isolated from lateral subventricular zone using visual guided micro-preparation under a dissection microscope (Zeiss, Jena, Germany, magnification 8x). About three mm of subventricular tissue was prepared with fresh scalpel blades, isolated with Dumont forceps and collected in ice cold HBSS-Glucose solution (HBSS from Gibco, 
Eggenstein, Germany) containing 300mg/ml D-glucose (Sigma, Deisenhofen, Germany). Cells from adjacent tissue not containing stem cells are generally not proliferating in growth promoting medium. Isolated tissue was digested with $1.33 \mathrm{mg} / \mathrm{ml}$ trypsin (Sigma, Deisenhofen, Germany), $0.7 \mathrm{mg} / \mathrm{ml}$ hyaluronidase (Sigma, Deisenhofen, Germany), 200u/ml DNAse (Sigma, Deisenhofen, Germany) and $0.2 \mathrm{mg} / \mathrm{ml}$ kynurenic acid (Sigma, Deisenhofen, Germany) for $30 \mathrm{~min}$ at $37^{\circ} \mathrm{C}$. Tissue was passed through a $70 \mu \mathrm{m}$ cell strainer (BD Falcon; Heidelberg, Germany) and transferred to ice cold EBSS containing $15 \mathrm{mM}$ HEPES and $0.04 \mathrm{~g} / \mathrm{ml}$ BSA to stop trypsin activity. NSCs were cultured in serum-free media (DMEM/F12, Gibco, Eggstein, Germany) containing basic fibroblast growth factor (bFGF; 20ng/ml, Chemicon, Hofheim, Germany), epidermal growth factor (EGF; 20ng/ml; R\&D Systems, Wiesbaden, Germany) and B27 supplement ( $60 \mu \mathrm{l} / \mathrm{ml}$, Gibco, Eggenstein, Germany). Primary neurospheres were dissociated at day 8-10 using Accutase (PAA, Pasching, Austria) to derive secondary neurospheres. Accutase combines protease and collagenolytic activities without need of additional washes or enzyme inhibitors after dissociation. The sub-culturing protocol consisted of neurosphere passaging every 3-4 days with whole culture media change (with freshly added growth factors).

\section{Immunocytochemistry}

Neurospheres were harvested on microscope slides by cytospin centrifugation $(212 \mathrm{~g}, 5 \mathrm{~min}$., Shandon, Thermo, Dreieich, Germany). Fixation was done by $3.7 \%$ formaldehyde, in water ( $\mathrm{pH} 7.5)$, for $60 \mathrm{~min}$ at $4^{\circ} \mathrm{C}$ followed by wash steps in $1 \mathrm{x}$ PBS for $5 \mathrm{~min}$. Blocking was done in $5 \%$ goat serum or $5 \%$ rabbit serum (for anti Notch 2 and anti DCX) for $30 \mathrm{~min}$ at $23^{\circ} \mathrm{C}$ followed by incubation with primary antibodies (see Table 1) at $23^{\circ} \mathrm{C}$. Detection was done with $\mathrm{Cy} 3$ conjugated antibodies (see Table 1, 1:300, $1 \mathrm{~h}$ at $23^{\circ} \mathrm{C}$, Jackson Immuno Research Laboratories, distributed by Dianova, Hamburg, Germany). Nuclear staining was done with SYTOX (1:10000, Molecular Probes, Göttingen, Germany). Antibody staining was visualized using confocal laser scanning microscopy (LSM Pascal, Zeiss, Jena, Germany).

\section{Aggregation assay (time-lapse videomicroscopy)}

Secondary neurospheres were harvested, dissociated with Accutase (see above) and stimulated with $10 \mathrm{ng} / \mathrm{ml}$ TNF in serum-free culture media described above. For pharmacological blockade cells were treated for $30 \mathrm{~min}$ with $100 \mu \mathrm{M}$ PDTC (Sigma, Deisenhofen, Germany) or 5 $\mu \mathrm{M}$ Bay11-7082 (Alexis Biochemicals, Grünberg, Germany). The chambers containing neural stem cells were heated continuously to $37^{\circ} \mathrm{C}$. Aggregation was recorded for up to 2 hours after TNF stimulation and analyzed using Corel R.A.V.E. (Corel Corporation) and ImageJ software (National Institute of Health, USA; http:/ /rsb.info.nih.gov/ij). Aggregation level was determined as the size of free space between cell aggregates. Maximal aggregation level was set as $100 \%$. Statistical significance was determined by ANOVA with Bonferroni correction, using GraphPad's Prism. $P \leq 0.05$ was considered significant.

Table 1. List of antibodies used for immunocytochemical staining of NSCs

\begin{tabular}{|c|c|c|c|c|c|}
\hline Antibody & Supplier & $\begin{array}{l}\text { Host } \\
\text { species }\end{array}$ & Dilution & $\begin{array}{l}\text { Incubation } \\
\text { time }\end{array}$ & Secondary Antibody \\
\hline anti Nestin & BD Pharmingen, Heidelberg, Germany & mouse & $1: 100$ & $1 \mathrm{~h}$ & $\begin{array}{l}\text { Cy3 conjugated Goat Anti- } \\
\text { Mouse IgG }(\mathrm{H}+\mathrm{L})\end{array}$ \\
\hline anti GFAP & BD Pharmingen, Heidelberg, Germany & mouse & $1: 100$ & $1 \mathrm{~h}$ & $\begin{array}{l}\text { Cy3 conjugated Goat Anti- } \\
\text { Mouse IgG }(\mathrm{H}+\mathrm{L})\end{array}$ \\
\hline anti beta-III-tubulin & Promega, Mannheim, Germany & mouse & $1: 50$ & $1 \mathrm{~h}$ & $\begin{array}{l}\text { Cy3 conjugated Goat Anti- } \\
\text { Mouse IgG }(\mathrm{H}+\mathrm{L})\end{array}$ \\
\hline anti TNF-RI & abcam, Cambridge, UK & rabbit & $1: 100$ & $1 \mathrm{~h}$ & $\begin{array}{l}\text { Cy3 conjugated Goat Anti- } \\
\text { Rabbit IgG }(\mathrm{H}+\mathrm{L})\end{array}$ \\
\hline anti TNF-RII & Alexis Biochemicals, Grünberg, Germany & mouse & $1: 100$ & $1 \mathrm{~h}$ & $\begin{array}{l}\text { Cy3 conjugated Goat Anti- } \\
\text { Mouse } \operatorname{IgG}(\mathrm{H}+\mathrm{L})\end{array}$ \\
\hline anti LeX & $\begin{array}{l}\text { Developmental Hybridoma Bank, Iowa City, } \\
\text { USA }\end{array}$ & rabbit & $1: 100$ & $1 \mathrm{~h}$ & $\begin{array}{l}\text { Cy3 conjugated Goat Anti- } \\
\text { Rabbit IgG }(\mathrm{H}+\mathrm{L})\end{array}$ \\
\hline anti Sox 2 & Sigma, Deisenhofen, Germany & rabbit & $1: 100$ & $1 \mathrm{~h}$ & $\begin{array}{l}\text { Cy3 conjugated Goat Anti- } \\
\text { Rabbit IgG }(\mathrm{H}+\mathrm{L})\end{array}$ \\
\hline anti Musashi & Chemicon, Hofheim, Germany & rabbit & $1: 100$ & $1 \mathrm{~h}$ & $\begin{array}{l}\text { Cy } 3 \text { conjugated Goat Anti- } \\
\text { Rabbit } \operatorname{IgG}(\mathrm{H}+\mathrm{L})\end{array}$ \\
\hline anti L1 & $\begin{array}{l}\text { Developmental Hybridoma Bank, Iowa City, } \\
\text { USA }\end{array}$ & mouse & $1: 100$ & $1 \mathrm{~h}$ & $\begin{array}{l}\text { Cy3 conjugated Goat Anti- } \\
\text { Mouse } \operatorname{IgG}(\mathrm{H}+\mathrm{L})\end{array}$ \\
\hline anti PSA & $\begin{array}{l}\text { Gift from Dr. Christoph Piechaczek, Miltenyi } \\
\text { Biotec, Bergisch Gladbach, Germany }\end{array}$ & mouse & $1: 50$ & $1 \mathrm{~h}$ & $\begin{array}{l}\text { Cy3 conjugated Goat Anti- } \\
\text { Mouse IgG }(\mathrm{H}+\mathrm{L})\end{array}$ \\
\hline anti Notch2 & Santa Cruz Biotechnology, Santa Cruz, USA & goat & $1: 50$ & $1 \mathrm{~h}$ & $\begin{array}{l}\text { Cy3 conjugated Rabbit } \\
\text { Anti-Goat } \operatorname{IgG}(\mathrm{H}+\mathrm{L})\end{array}$ \\
\hline anti A2B5 & Chemicon, Hofheim, Germany & mouse & $1: 100$ & $1 \mathrm{~h}$ & $\begin{array}{l}\text { Cy3 conjugated Goat Anti- } \\
\text { Mouse } \operatorname{IgG}(\mathrm{H}+\mathrm{L})\end{array}$ \\
\hline anti DCX & Santa Cruz Biotechnology, Santa Cruz, USA & goat & $1: 50$ & $1 \mathrm{~h}$ & $\begin{array}{l}\text { Cy3 conjugated Rabbit } \\
\text { Anti-Goat } \operatorname{IgG}(\mathrm{H}+\mathrm{L})\end{array}$ \\
\hline
\end{tabular}




\section{Detection of nuclear NF-אB in TNF stimulated neural stem cells}

Neurospheres were stimulated with $10 \mathrm{ng} / \mathrm{ml} \mathrm{TNF}$. $45 \mathrm{~min}$ after TNF stimulus cells were harvested and fixed as described above. After 30min of permeabilisation with $0.5 \%$ TritonX100/PBS and blocking with $5 \%$ goat serum cells were stained with anti-p65 antibody (Chemicon, Hofheim, Germany, 1:50). Detection was done with Cy3 conjugated anti-mouse antibody (1:300, Jackson Immuno Research Laboratories, distributed by Dianova, Hamburg, Germany). Nuclear staining was done with SYTOX (1:10000, Molecular Probes, Göttingen, Germany). Antibody staining was visualized using confocal laser scanning microscopy (LSM Pascal, Zeiss, Jena, Germany).

\section{Loss of function assay}

Neurospheres were dissociated as described above and transfected using Rat NSC Nucleofector Kit (Amaxa, Köln, Germany). Namely, 5.00 E+6 cells were resuspended in $100 \mu 1$ of Nucleofector solution. After adding of DNA the suspension was transferred into Amaxa cuvette and transfected using Nucleofector II device (Program A:33,). The transfected cells were transferred in medium filled $15 \mathrm{ml}$ conical tube followed by centrifugation for $10 \mathrm{~min}$ at $212 \mathrm{x} \mathrm{g}$. After centrifugation cells were resuspended in $3 \mathrm{ml}$ medium and cultured at $37^{\circ} \mathrm{C}$. To monitor the transfection efficacy cells were transfected with pmaxGFP (Amaxa, Köln, Germany) or pmaxFP red. After $24 \mathrm{~h}$ of culture at $37^{\circ} \mathrm{C}$ cells were harvested by means of cytospin centrifugation, fixed as described above and stained for DNA. Here, pmaxGFP transfected cells were stained with DRAQ5 (1:300, 30min, $23^{\circ} \mathrm{C}$, Molecular Probes, Göttingen, Germany). DNA staining of pmaxFP red transfected cells was done with SYTOX (1:10000, Molecular Probes, Göttingen, Germany). DNA staining was visualized using confocal laser scanning microscopy (LSM Pascal, Zeiss, Jena, Germany). Transfection efficacy was quantified by counting of total cell number vs. number of transfected cells. Because of the usually lower red fluorescence (compared to the green channel) we quantified events of single channels and not the merged images. This method assures proper cell number determination and avoids false positive or negative counts potentially suggested by merged images.

To investigate the influence of blockade of NF- $\mathrm{NB}$ pathway on aggregation of TNF stimulated $v s$. unstimulated neural stem cells, IкB-AA1 (super-repressor

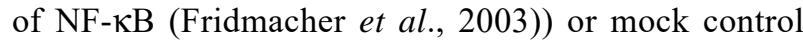
vector pMET (Invitrogen, Eggenstein, Germany) was cotransfected with pmaxFP red vector. Transfection efficiency was determined by detection of pmaxFP red and analysis by confocal laser scanning microscopy (LSM Pascal, Zeiss, Jena, Germany). To avoid additional stress for the cells all experiments with transfected cells were done in chambers continuously heated to $30^{\circ} \mathrm{C}$ instead of $37^{\circ} \mathrm{C}$. After $2 \mathrm{~h}$ of incubation, total number of visible aggregates larger then 2 cells was determined. Statistical significance was determined by ANOVA with Bonferroni
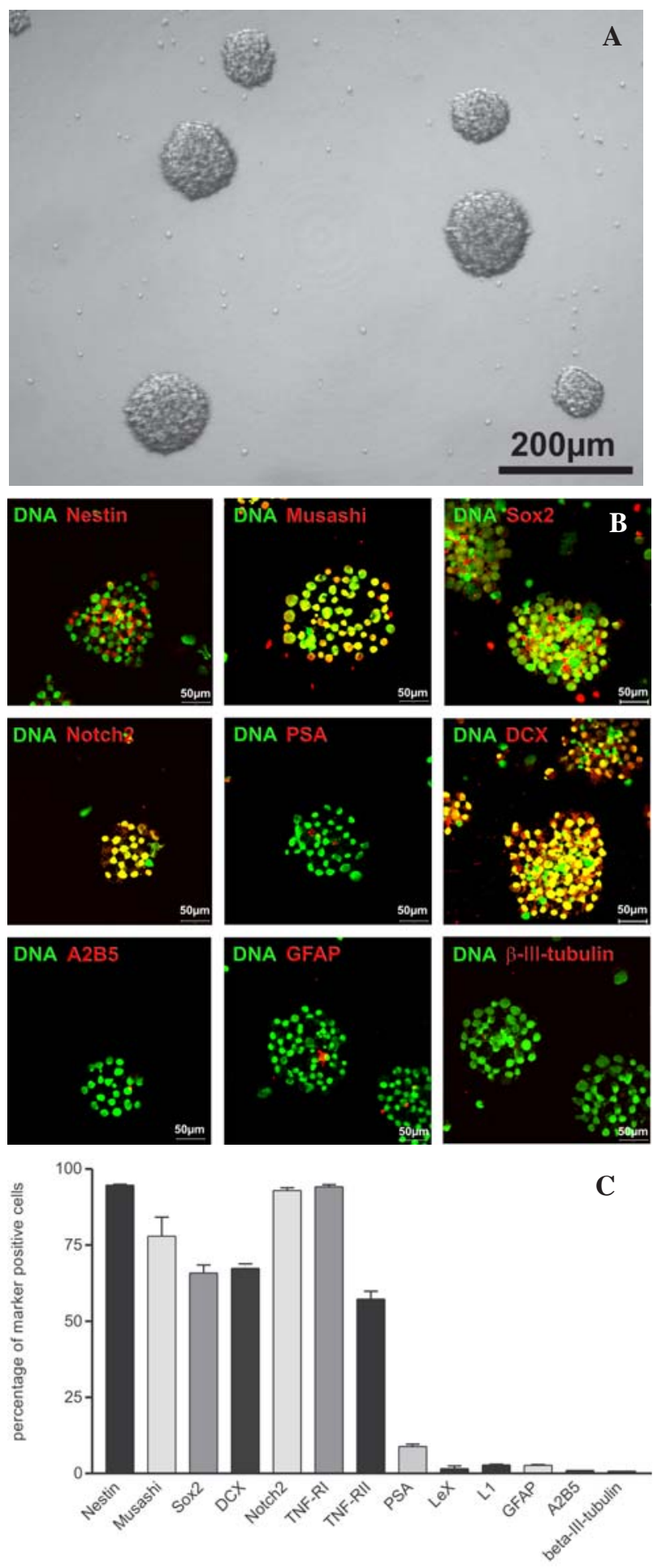

Figure 2. Characterization of neurosphere cultures (A) Phase contrast image of Neurosphere culture (B) Expression pattern of cultured, rat derived neurospheres. Neurospheres were collected on glass slides by cytospin centrifugation, fixed and stained for Nestin, Sox2, DCX, Musashi, PSA-NCAM, A2B5, GFAP and beta-III-tubulin. DNA was stained using SYTOX (green). Majority of the analyzed cells were positive for Nestin, Sox2, DCX, Musashi and Notch2 and negative for PSA-NCAM and differentiation markers A2B5 for oligodendrocyte progenitors, GFAP for glial cells and beta-III-tubulin (TuJ) for immature neurons. Bars, $50 \mu \mathrm{m}$. (C) Quantification of the expression pattern of adult neurosphere cultures. 

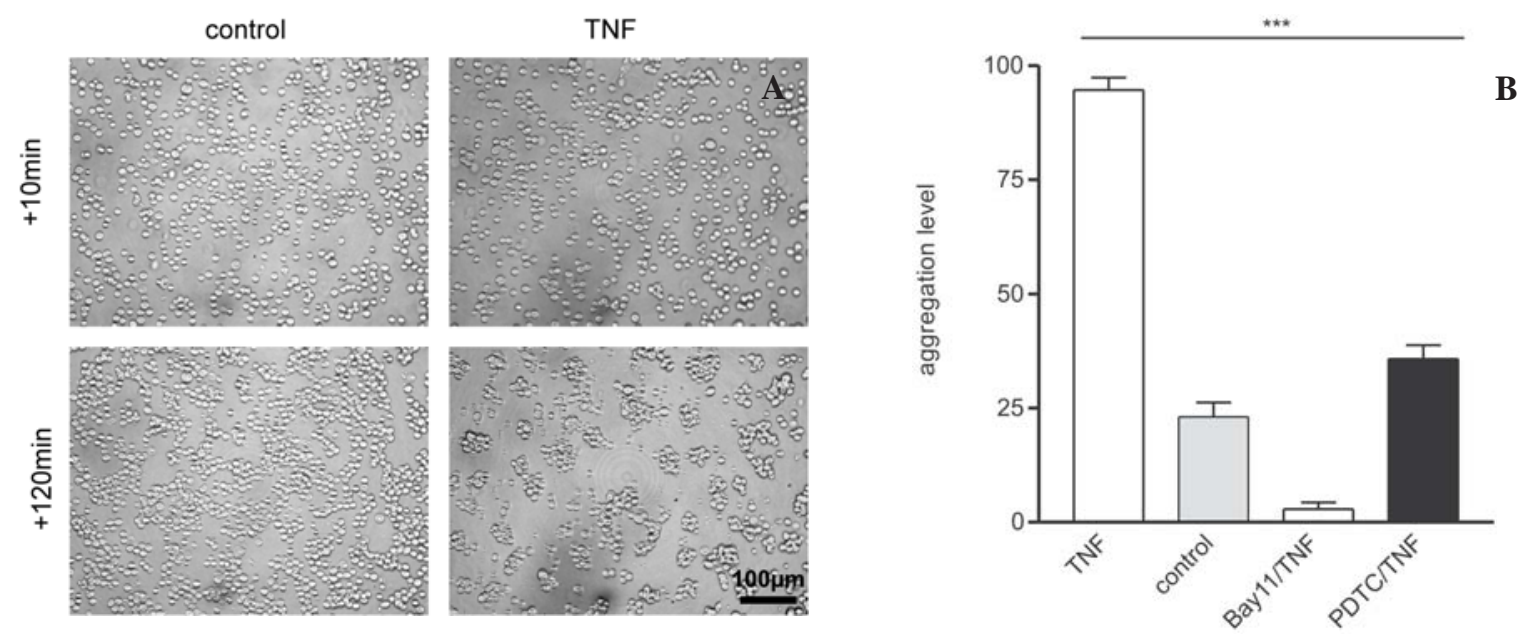

Figure 3. TNF induces enhanced aggregation of neural stem cells. (A) Summary of a time lapse video showing control neural stem cells 10min after TNF treatment (upper panel) and after 120min of recording (lower panel). Whole video sequences are available as supplementary video files. (B) Quantification of aggregation level. Please note the inhibition of TNF induced aggregation by pharmacological blockade of NF- $\mathrm{B}$ pathway via PDTC and Bay11-7082 (***P<0.001).
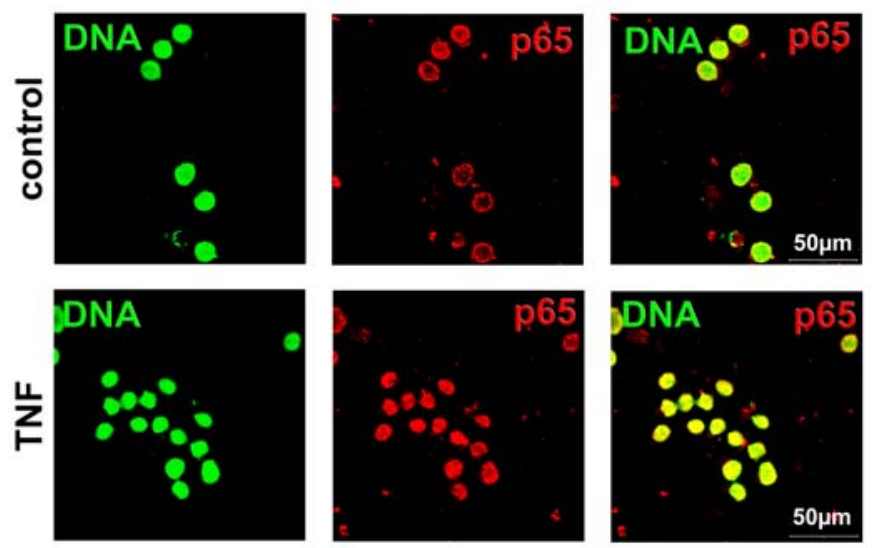

Figure 4. TNF activates NF-אB in NSCs as measured by nuclear translocation of p65 subunit. Nuclei were stained with SYTOX (green). Activity-specific anti-p65 immunoreactivity is depicted in red (middle panel). Merged images are shown on the right. Please note the low basal NF- $\mathrm{B}$ activity in unstimulated cells (upper panel). Bar depicts a size of $50 \mu \mathrm{m}$.

correction, using GraphPad's Prism. $\mathrm{P} \leq 0.05$ was considered significant.

\section{Results}

\section{Characterization of adult neural stem cells cultured as neurospheres}

Adult neural stem cells were cultured as 3D neurospheres (Fig. 2A and additional movie file. Please note the high motility of the cells and filopodia extending from 3D spheres capturing single cells). First, we investigated the expression pattern of neurosphere cultures isolated from the subventricular zone of adult rats (Fig 2B). The majority of the NSCs were positive for the intermediate filament Nestin, characteristic for neural stem cells. In addition they expressed the neural stem cell identity marker SOX2. The here used NSCs also expressed doublecortin (DCX), a marker for newborn immature neurons, which is detected in proliferating neural stem cells as well, and the RNA binding protein Musashi, essential for neurosphere formation and proliferation. No expression was detected for L1, LeX and for the oligodendrocytic lineage marker A2B5. Furthermore some cells were positive for PSANCAM, the poly-sialyated form of NCAM. We detected very low level of GFAP $(2.6 \% \pm 0.5)$ expression. Demonstrably, there was no detected expression of differentiation marker $\beta$-III-tubulin for immature neurons. In addition, the majority of NSCs was immuno-positive for TNF receptors I and II. Taken together, classically cultured neurospheres are heterogeneous in marker gene expression as shown in Figure $1 \mathrm{~B}$ and $\mathrm{C}$.

\section{TNF enhances NSC aggregation}

We used live imaging to investigate the behaviour of cells derived from dissociated neurospheres (Fig. 3). TNF treatment activated a faster aggregation of neurosphere derived cells than observed in control cells (see additional movie files and Fig. 3A; please compare summary of the time-lapse on the left panels under control condition with time-lapse summary after TNF treatment in the right panels). Quantification of aggregation showed a more than four-fold increase after TNF treatment (Fig. 3B). Next, we investigated the activation of the very well described 

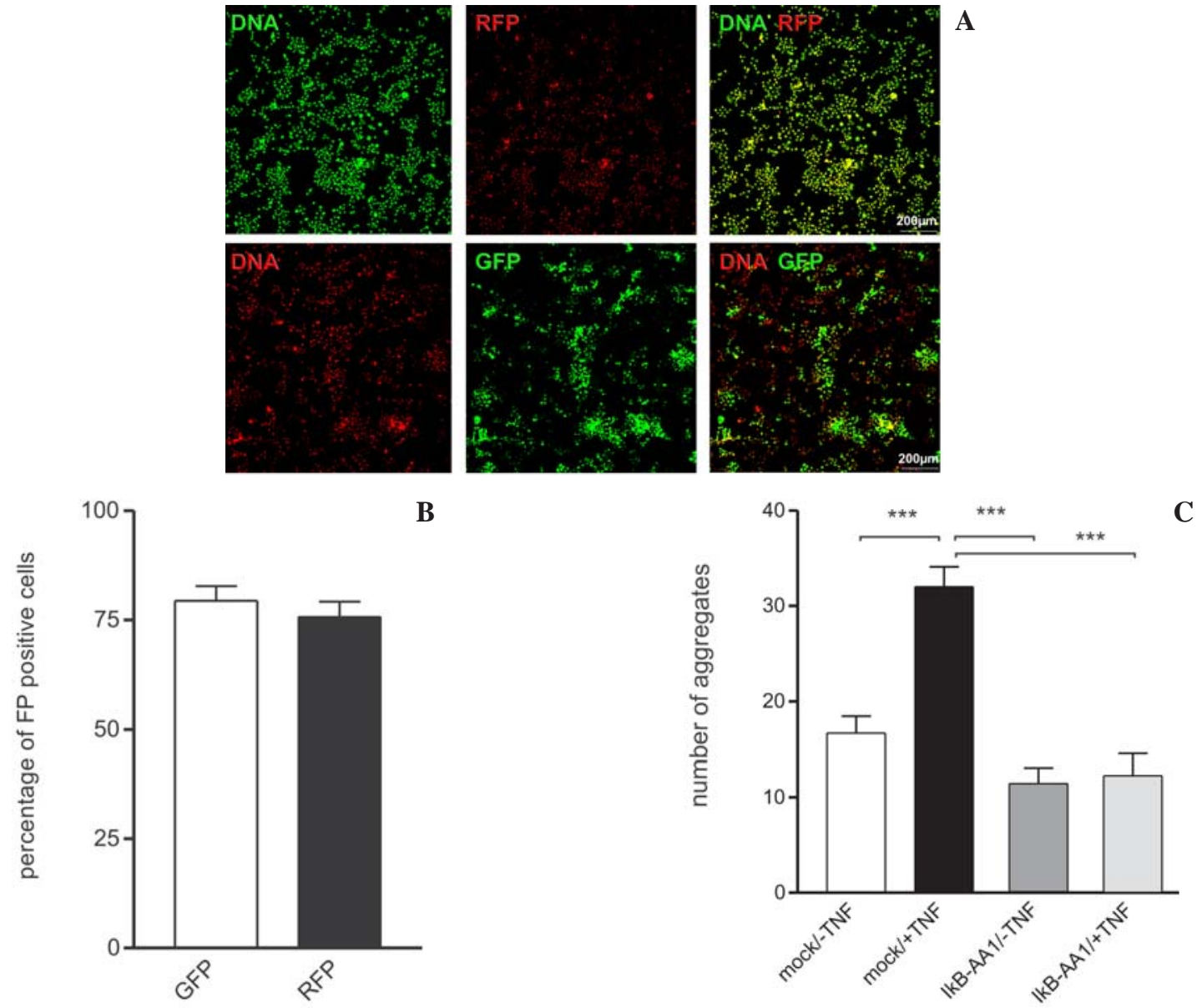

Figure 5. Genetic inhibition of NF-kB activation abolishes aggregation of NSCs. (A) Establishment of high efficacy transfection. Transfection efficacy was measured with CMV-driven FP (fluorescent protein) expression plasmids. Left panel depicts DNA visualized by SYTOX (green) or DRAQ-5 (lower image). Middle images show FP expression. Both images are merged in the right panel. Bar depicts a size of $200 \mu \mathrm{m}$. (B) Quantification of fluorescent protein expression. Please note the comparable transfection efficacies using different plasmids. (C) Transcriptional blockade of the NF- $\kappa \mathrm{B}$ pathway results in decreased re-aggregation tendency of NSCs. Please note that trans-dominant negative repressor IKB-AA1 transfected cells show no accelerated re-aggregation in response to TNF stimulus. $(* * * \mathrm{P}<0.0001)$.
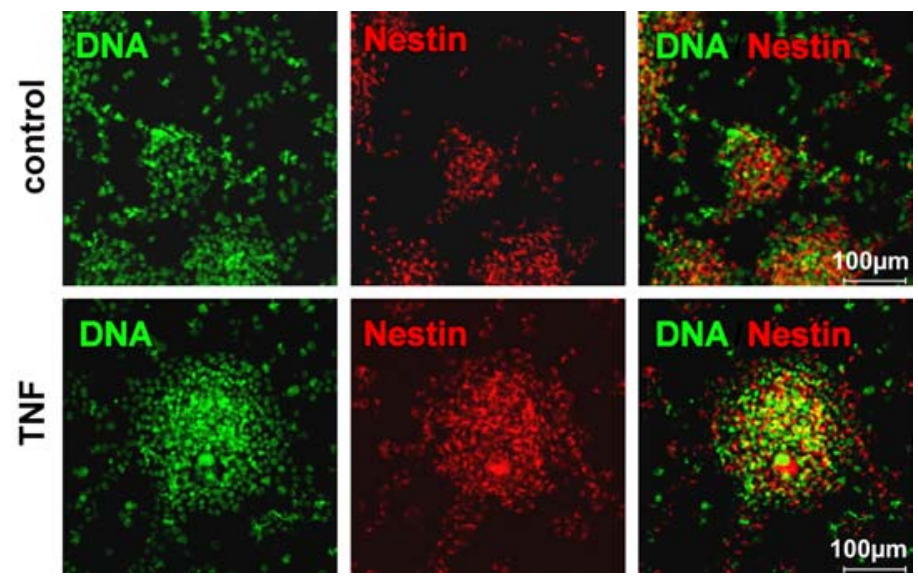

Figure 6. TNF does not alter the undifferentiated state of neural stem cells. $48 \mathrm{~h}$ after stimulation, TNF treated (lower panel) and untreated control neurospheres (upper panel) were collected on glass slides by cytospin centrifugation, fixed and stained for Nestin as described in Material and methods. Corresponding SYTOX staining for DNA is shown in green. Note that TNF does not change expression of Nestin. Bars depict a size of $100 \mu \mathrm{m}$. 
transcription factor NF- $\kappa$ B by TNF to explain the observed phenomenon on a molecular basis. Inhibition of the NF$\kappa \mathrm{B}$ activation pathway by two IKK inhibiting drugs (Bay11-7082 or PDTC) blunted the TNF activated aggregation. The effect of Bay11-7082 was stronger than that caused by PDTC (Fig. 3B).

\section{TNF activates NF- $\mathrm{KB}$ in neural stem cells}

In order to verify the NF- $\kappa B$ activation by TNF we used an activity-specific antibody against the NF- $\kappa B$ subunit p65. During the activated state of the transcription factor $\mathrm{NF}-\kappa \mathrm{B}$, its two subunits p65 and p50 are located in the nucleus. To investigate the sub-cellular distribution of NF$\kappa \mathrm{B}$ p65 on single cell level, NSCs were fixed and immunostained with an anti-p65-antibody (Fig. 4). This activation-specific antibody can only react with the p65 nuclear localization signal, when the repressing I $\mathrm{KB}$ protein is not present. TNF treated NSCs showed an increased nuclear localization of p65 (Fig. 4, lower panels). Thus, the distribution pattern correlates with the activation and thereby presents a way to confirm NF- $\mathrm{KB}$ activity.

\section{Genetic inhibition of NF-KB activation abolishes aggregation of NSCs}

In order to validate the results obtained by a pharmacological blockade of NF- $\mathrm{KB}$, we used genetic interference with the activation of $N F-\kappa B$. A

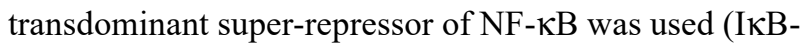
AA1). This super-repressor protein cannot be degraded by the proteasome, since the inducible phosphorylation sites: serines 32 and 36 were mutated to alanins. Comparably to results obtained using a pharmacological inhibition, blockade of NF- $\kappa B$ by transfection with the trans-dominant negative repressor IאB-AA1, led to decreased aggregation tendency (See Figure 5C). Moreover, IKB-AA 1 transfected cells showed no accelerated reaggregation in response to TNF stimulus

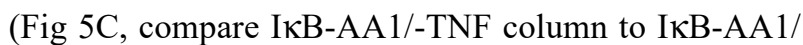
$+\mathrm{TNF})$.

\section{TNF - accelerated aggregation does not alter the undifferentiated state of neural stem cells}

Next, we wanted to analyze the effects of accelerated aggregation on the differentiation of NSCs. We used the general neural stem cell marker Nestin to analyze TNF treated NSCs in comparison to control cultures. In addition, we used an antibody against glial fibrillary acidic protein (GFAP), which is considered as a marker for astrocytes and anti $\beta$-III-tubulin for neurons. Neurospheres were positive for Nestin (Fig. 6) and the expression of this marker did not change after TNF treatment. As expected, neurospheres were negative for the neuronal marker $\beta$-III-tubulin (data not shown). TNF did not increase GFAP expression (data not shown). Thus, enhanced aggregation might not influence the undifferentiated state of NSCs.

\section{Supplementary video files \\ (available on the website)}

\section{File 1: 3Dneurosphere_culture.mpg}

Time-lapse of 2 hours of 3D neurosphere culture. Please note the high motility and the formation of filopodia for recruiting single cells to neurospheres.

\section{File 2: control.mpg}

Reaggregation of untreated neural stem cells (time-lapse video of 2 hours in culture).

File 3: TNF.mpg

Accelerated reaggregation of TNF treated cultures.

\section{Discussion}

To our knowledge, this is the first report on dependence of aggregation and reaggregation of NSCs on activated NF-KB. It is well known that cultured NSCs form self-

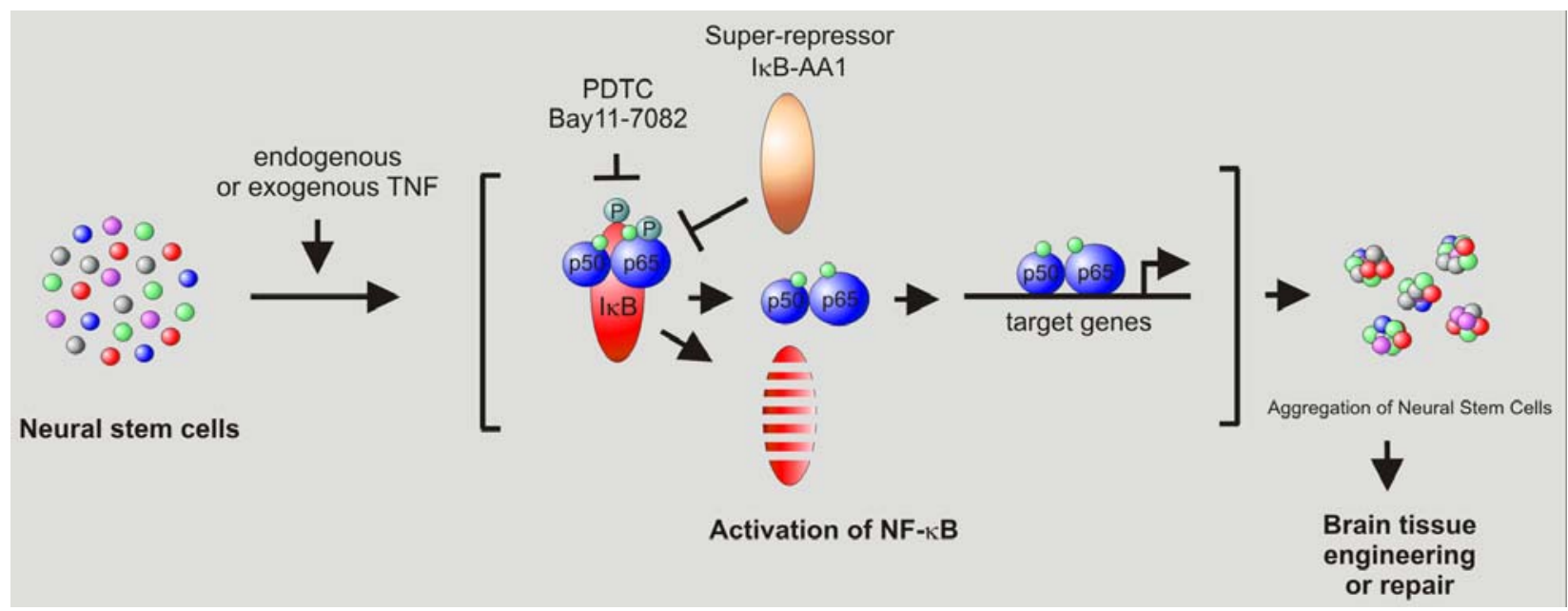

Figure 7. Model for NF-KB dependend acceleration of 3D neurosphere formation. Dissociated neural stem cells reaggregate in an NF- $\kappa \mathrm{B}$ dependent manner. Exogenously added TNF does accelerate significantly the 3D sphere formation. This effect can be blocked by both - transcriptional blockade by the super-repressor IkB-AA1 and pharmacological blockade. We propose the use of TNF- $\alpha$ as additional culture component for fast neurosphere formation. 
adherent clusters called neurospheres. NSCs are able to grow as adherent cells as well, but this culture setup requires the use of coated culture containers, e.g. with poly-D-lysine. The interaction of extra-cellular matrix with intra-cellular signal transduction cascades caused by these protocols may distort the results of several assays. Therefore there is a need for 3D neurospheres cultures, which imitate in limited way the endogenous niche of NSCs by cell-cell interaction (for discussion see Layer et al., 2002).

In this approach, we tested the influence of TNF- $\alpha$ on motility and aggregation of neurospheres derived NSCs. Here we observed a significantly enhanced aggregation grade in TNF treated cultures compared to controls. Due to the fact that TNF- $\alpha$ is inducing the transcription factor $\mathrm{NF}-\kappa \mathrm{B}$, we investigated the influence of pharmacological and transcriptional blockade of NF$\kappa \mathrm{B}$ on neurosphere formation. First, we demonstrated strong activation of NF- $\kappa \mathrm{B}$ by TNF, observable as predominantly nuclear localisation of the transcription factor after treatment. In addition, we were able to show that isolated, TNF treated cells show boosted tendency to aggregate compared to untreated controls. Furthermore, pharmacological blockade of the NF- $\kappa B$ pathway by welldescribed specific NF- $\kappa$ B inhibiting drugs, PDTC and Bay 11-7082, significantly reduced the aggregation of NSCs. In accordance with our hypothesis of NF- $\mathrm{KB}$ dependent

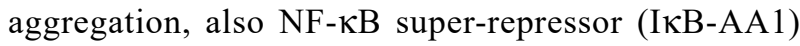
transfected cells showed a significantly decreased tendency to aggregate. It seems very unlikely that the fast aggregation is due to chemotactic migration. MCP-1 (Widera et al., 2004) and SCF (Sun et al., 2004) induced migration of neural stem cells was only observed after $>3 \mathrm{~h}$ and not as rapidly as has been demonstrated here as reaggregation. In addition the rapid reaggregation will interfere with migration assays e.g. Boyden chamber assays.

Beside of the published action on induction of migration by chemokines such as, SCF (Sun et al., 2004), SDF-1 $\alpha$ (Imitola et al., 2004), MCP-1 (Widera et al., 2004) and PDGF (Forsberg-Nilsson et al., 1998) the role of $\mathrm{NF}-\kappa \mathrm{B}$ and its targets on neural stem cells differentiation and proliferation are currently under investigation.

In spite of relatively well established protocols for adult neural stem cell cultivation there is need for further improvements of culture procedures and methods. Fast 3D neurosphere formation in stem cell based assays is crucial for both - in vitro tissue engineering and potential therapeutic use. This study demonstrates faster 3D culture formation in TNF- $\alpha$ containing approaches, compared to standard protocols. Importantly, TNF and NF- $\kappa \mathrm{B}$ activation had no effect on stemness of 3D neurospheres. In Figure 7 we propose a novel standard protocol for neurosphere based research. We suggest the use of TNF$\alpha$ as a novel cytokine in all assays that require fast 3D neurosphere formation. The findings presented here may provide a novel outlook in neural stem cell research and tissue engineering.
An important extrinsic factor determining cell fate in addition to cytokines, growth factors etc. is the cell surrounding nanoscale (structures with $\mathrm{nm}$ diameter) extracellular matrix (ECM), which is essential for guidance through distinct developmental pathways. Artificial biomaterial scaffolds, which are designed to support cell and tissue growth, are traditionally within a macroscale $(\mathrm{mm}$ to $\mathrm{cm})$. Neurospheres provide a natural 3D scaffold consisting of cell-cell interactions and potential cell-ECM interaction (Campos, 2004). Thus the here used 3D-neurosphere culture paradigm might have the advantages to provide a natural support for growing of NSCs in an undifferentiated state. In addition, the 3D neurospheres might be well suited for direct transfer to brain without additional support by scaffolds. Since scaffolds could impose special routes of cellular differentiation (Stevens and George, 2005), it might be of advantage to use NSCs without such artificial nanoscale scaffolds to avoid such unnatural route of differentiation.

On the other hand, the development of scaffolds for tissue engineering has made a fantastic progress. Stevens and George (Stevens and George, 2005) discuss 3 types of scaffolds in use for tissue engineering: micropore scaffolds such as hydrogels or crystalline structures, microfibre scaffolds which could be spun from nonfibres and nanofibre scaffolds made from synthetic or natural polymers. Indeed, a micropore scaffold made from alginate could be successfully used to combine endothelial cells and NSCs for brain implanted engineering (Ford et al., 2006). The combined cells provided an efficient neovascularization for the brain implanted NSCs. Furthermore, a 3D aragonite biomatrix obtained from the exoskeleton of a coral provided a scaffold for the cultivation of hippocampal neurons (Shany et al., 2005). A peptide nanofibre scaffold was used to harvest hippocampal neural progenitors from cultivated hippocampal brain slices (Semino et al., 2004). Furthermore Silva et al. (2004) provide evidence for enhanced neuronal differentiation after exposure of neural stem cells with neurite extending peptide-decorated nanofibres.

We see a main advantage for the use of potentially biodegradable scaffolds in a way to provide support to NSCs in two ways: avoiding drying out during operation and fixation to the site where operative reconstruction is intended. The here described neurosphere culture paradigm might be a way to generate large amounts of undifferentiated neural stem cells which generate a potent combination with artificial or natural scaffolds.

\section{Acknowledgements:}

This study was supported in part by the Deutsche Forschungsgemeinschaft (DFG). We thank Thomas Dittmar for help with the Amaxa transfection system. The excellent technical help of Julia Pfeiffer and Maria Prüllage is greatly acknowledged. The antibodies developed by Patterson, P. H., Jessell, T. M., Dodd, J. and 
Artavanis- Tsakonas, S. were obtained from the Developmental Studies Hybridoma Bank developed under the auspices of the NICHD and maintained by The University of Iowa, Department of Biological Sciences, Iowa City, IA 52242. Anti-PSA antibody was obtained from Dr. Christoph Piechaczek, Miltenyi Biotec, Bergisch Gladbach, Germany.

\section{References}

Brazel CY, Limke TL, Osborne JK, Miura T, Cai J, Pevny L, Rao MS (2005) Sox2 expression defines a heterogeneous population of neurosphere-forming cells in the adult murine brain. Aging Cell 4: 197-207.

Campos LS (2004) Neurospheres: insights into neural stem cell biology. J Neurosci Res 78: 761-9.

Doetsch F, Caille I, Lim, DA, Garcia-Verdugo JM, Alvarez-Buylla A (1999) Subventricular zone astrocytes are neural stem cells in the adult mammalian brain. Cell 97: 703-716.

Ford MC, Bertram JP, Hynes SR, Michaud M, Li Q, Young M, Segal SS, Madri JA, Lavik EB (2006) A macroporous hydrogel for the coculture of neural progenitor and endothelial cells to form functional vascular networks in vivo. Proc Natl Acad Sci U S A 103: 2512-2517.

Forsberg-Nilsson K, Behar TN, Afrakhte M, Barker JL, McKay RD (1998) Platelet-derived growth factor induces chemotaxis of neuroepithelial stem cells. J Neurosci Res 53: 521-530.

Fridmacher V, Kaltschmidt B, Goudeau B, Ndiaye D, Rossi FM, Pfeiffer J, Kaltschmidt C, Israel A, Memet S (2003) Forebrain-specific neuronal inhibition of nuclear factor-kappaB activity leads to loss of neuroprotection. J Neurosci 23: 9403-9408.

Gage FH (2000) Mammalian neural stem cells. Science 287: 1433-1438.

Heine W, Conant K, Griffin JW, Hoke A (2004) Transplanted neural stem cells promote axonal regeneration through chronically denervated peripheral nerves. Exp Neurol 189: 231-240.

Imitola J, Raddassi K, Park KI, Mueller FJ, Nieto M, Teng YD, Frenkel D, Li J, Sidman RL, Walsh CA, Snyder EY, Khoury SJ (2004) Directed migration of neural stem cells to sites of CNS injury by the stromal cell-derived factor 1alpha/CXC chemokine receptor 4 pathway. Proc Natl Acad Sci U S A 101: 18117-18122.

Johansson CB, Momma S, Clarke DL, Risling M, Lendahl U, Frisen J (1999) Identification of a neural stem cell in the adult mammalian central nervous system. Cell 96: $25-34$.

Kaltschmidt B, Widera D, Kaltschmidt C (2005) Signaling via NF-kappaB in the nervous system. Biochim Biophys Acta 1745: 287-299.

Layer PG, Robitzki A, Rothermel A, Willbold E (2002) Of layers and spheres: the reaggregate approach in tissue engineering. TINS 25: 131-134.

Lendahl U, Zimmerman LB, McKay RD (1990) CNS stem cells express a new class of intermediate filament protein. Cell 60: 585-595.
McKay R (1997) Stem cells in the central nervous system. Science 276: 66-71.

Pevny LH, Sockanathan S, Placzek M, Lovell-Badge R. (1998) A role for SOX1 in neural determination. Development 125: 1967-1978.

Pluchino S, Zanotti L, Rossi B, Brambilla E, Ottoboni L, Salani G, Martinello M, Cattalini A, Bergami A, Furlan R, Comi G, Constantin G, Martino G (2005) Neurospherederived multipotent precursors promote neuroprotection by an immunomodulatory mechanism. Nature 436: 266271.

Rao MS (1999) Multipotent and restricted precursors in the central nervous system. Anat Rec 257: 137-148.

Reynolds BA, Weiss S (1992) Generation of neurons and astrocytes from isolated cells of the adult mammalian central nervous system. Science 255: 1707-1710.

Roy NS, Wang S, Jiang L, Kang J, Benraiss A, Harrison-Restelli C, Fraser RA, Couldwell WT, Kawaguchi A, Okano H, Nedergaard M, Goldman SA (2000) In vitro neurogenesis by progenitor cells isolated from the adult human hippocampus. Nat Med 6: 271-277.

Sakakibara S, Imai T, Hamaguchi K, Okabe M, Aruga J, Nakajima K, Yasutomi D, Nagata T, Kurihara Y, Uesugi S, Miyata T, Ogawa M, Mikoshiba K, Okano H (1996) Mouse-Musashi-1, a neural RNA-binding protein highly enriched in the mammalian CNS stem cell. Dev Biol 176: 230-242.

Sakakibara S, Nakamura Y, Yoshida T, Shibata S, Koike M, Takano H, Ueda S, Uchiyama Y, Noda T, Okano H (2002) RNA-binding protein Musashi family: roles for CNS stem cells and a subpopulation of ependymal cells revealed by targeted disruption and antisense ablation. Proc Natl Acad Sci U S A 99: 15194-15199.

Semino CE, Kasahara J, Hayashi Y, Zhang S (2004) Entrapment of migrating hippocampal neural cells in three-dimensional peptide nanofiber scaffold. Tissue Eng 10: $643-655$.

Shany B, Vago R, Baranes D (2005) Growth of primary hippocampal neuronal tissue on an aragonite crystalline biomatrix. Tissue Eng 11: 585-596.

Stevens MM, George JH (2005) Exploring and engineering the cell surface interface. Science 310: 1135 1138 .

Silva GA, Czeisler C, Niece KL, Beniash E, Harrington DA, Kessler JA, Stupp SI (2004) Selective Differentiation of Neural Progenitor Cells by HighEpitope Density Nanofibers. Science 303: 1352-1355.

Sun L, Lee J, Fine HA (2004) Neuronally expressed stem cell factor induces neural stem cell migration to areas of brain injury. J Clin Invest 113: 1364-1374.

Widera D, Holtkamp W, Entschladen F, Niggemann B, Zanker K, Kaltschmidt B, Kaltschmidt C (2004). MCP1 induces migration of adult neural stem cells. Eur J Cell Biol 83: 381-387.

Widera D, Mikenberg I, Kaltschmidt B, Kaltschmidt C. (2006) Potential role of NF-kappaB in adult neural stem cells: the underrated steersman? Int J Dev Neurosci 24: 91-102. 


\section{Discussion with Reviewers}

M.Stoddart: The idea of brain tissue engineering is a fascinating one; do you think the scaffold free approach taken here is likely to be more successful than approaches that use scaffolds?

Authors: We, don't think that these are alternatives but complementary strategies. The here described scaffoldfree approach using neurospheres might be a way to generate large numbers of undifferentiated cells. For therapeutic use, it might be better to use these cells in combination with suitable scaffolds such as porous gels or microfibre textiles. This could give the advantage to fix the cells initially to the site of the lesion and might provide a better survival of neural stem cells. On the other hand, due to the migratory activity, neurospheres without scaffold can be introduced in blood flow and can cross the blood brain barrier in inflammatory brain diseases. Thus in such cases a scaffold free approach might be better.
M.Stoddart: How do you think a suitable structure might be achieved?

Authors: This might be dependent on the lesion, which should be reengineered. In a trauma situation where cells should be transplanted within a region destroyed by a cortical impact, a scaffold containing neurospheres and endothelial cells might be of advantage to restore the impaired blood flow and help the survival of the transplanted neurospheres. This could be achieved using a hydrogel or a network of nanofibres. If needed coating of nanofibres might be a way to trigger differentiation in selected lineages. Another situation might be an inflammatory brain disease like Multiple Sclerosis. In this case different areas of lesions should be repaired and this can be more efficiently done with migrating stem cells without scaffolds. 